\title{
The Priolo Atlas: A citizen science-based census initiative for supporting Pyrrhula murina habitat conservation and restoration policies in São Miguel Island (Azores, Portugal)
}

\author{
Artur Gil ${ }^{\mathrm{a}, *}$, Ricardo Ceia ${ }^{\mathrm{b}}$, Rúben Coelho ${ }^{\mathrm{c}}$, Joaquim Teodósio ${ }^{\mathrm{c}}$, Hugo Sampaio ${ }^{\mathrm{c}}$, \\ Carla Veríssimo $^{c}$, Ruben Heleno ${ }^{\mathrm{d}}$, Jaime Ramos ${ }^{\mathrm{b}}$, Sérgio Timóteo ${ }^{\mathrm{d}, \mathrm{e}}$ \\ ${ }^{a}$ CE3C - Centre for Ecology, Evolution and Environmental Changes, Azorean Biodiversity Group, Department of Biology, University of the Azores, \\ 9501-801 Ponta Delgada, Portugal \\ ${ }^{\mathrm{b}}$ MARE - Marine and Environmental Sciences Centre, Department of Life Sciences, University of Coimbra, 3004-517 Coimbra, Portugal \\ c SPEA - Portuguese Society for the Study of Birds, Avenida João Crisóstomo, 18, $4 \circ$ Direito, 1000-179 Lisboa, Portugal \\ ${ }^{\mathrm{d}}$ CFE - Centre for Functional Ecology, Department of Life Sciences, University of Coimbra, Calçada Martim de Freitas, 3001-456 Coimbra, Portugal \\ e School of Biological Sciences, University of Bristol, Life Sciences Building, 24 Tyndall Avenue, Bristol BS8 1TQ UK
}

\section{A R T I C L E I N F O}

\section{Article history:}

Received 22 June 2015

Received in revised form 14 October 2015

Accepted 25 October 2015

Keywords:

Volunteered geographic information

Bird census

Population trends

Range size

Azores Bullfinch

\begin{abstract}
A B S T R A C T
The endemic Azores Bullfinch or Priolo (Pyrrhula murina) is one of the most threatened European passerines, historically restricted to a single population in the Pico da Vara/Ribeira do Guilherme Special Protection Area (São Miguel Island, Azores, Portugal). Annual census of this species started in 1991. It usually took one observer 1-2 months to complete the census and even then, it was not logistically reasonable to include some areas with very steep slope in the core of the protected area. In order to bypass these constraints, an alternative and ambitious monitoring scheme that would allow estimating the whole species throughout its entire range was proposed in 2007. The new scheme, which complemented and improved previous estimates, consisted in performing a thorough instantaneous census using a distance sampling approach, thus allowing a detailed snapshot of effective occupation, density, habitat preferences and distribution range of the Azores Bullfinch. The Priolo Atlas turned into a volunteered geographic information and citizen science-based ornithological initiative which every 4 years congregates more than 50 well-trained volunteers in the Azores. With the first two editions (2008 and 2012), this initiative has already established itself as a critical tool to monitor the population of this endemic species.
\end{abstract}

(c) 2015 Elsevier B.V. All rights reserved.

\section{Introduction}

\subsection{Volunteered geographic information and citizen} science-based ornithological initiatives

The field of conservation ecology has evolved tremendously over the last decades and is now a well-established scientific area where rigorous scientific methods are applied to permanently inform adaptive conservation management (McCarthy and Possingham, 2007). While the advantages of adaptive management based on sound scientific evidence has proved extremely effective, its implementation is constrained by the need of compiling appropriate datasets capable of reflecting ecosystems diversity in time and

\footnotetext{
* Corresponding author.

E-mail address: arturgil@uac.pt (A. Gil).
}

space. Citizen science - scientific research performed in part or in whole by volunteers (Newman et al., 2010; Robson, 2012; Cooper et al., 2014; Morzy, 2014) - has thus emerged as a most valuable solution to gather such large datasets (Devictor et al., 2010). The practice of citizen involvement in scientific projects is not really new (Cohn, 2008), especially in environmental monitoring projects, including biodiversity (Nascimento et al., 2014). Geographic data are increasingly provided by individuals, who in most cases are not trained or even necessarily interested in geography as a science. This marks a trend toward increasing publicly volunteered geographic information (VGI), where various forms of geographic data are provided voluntarily by individuals (Goodchild, 2007). VGI has several advantages over data collected by professional scientists, namely a relatively low cost to implement, a potentially large set of samples gathered, the potential to have data collected from across a wider geographic area than a single scientist can cover, and also a potentially fine resolution of data. Nevertheless, a further challenge 
of VGI is that there may be little top-down control of data gathering and thus a greater potential for errors and user biases to creep in, unless explicit protocols are developed for data collection along with post hoc data filtering (Wiersma, 2010). In fact, according to Goodchild (2007), the concept of an experimental control goes somewhat against the spirit of VGI, which emphasizes independence, democratization, and individuality. Nevertheless, Dickenson et al. (2010) suggest that VGI projects can complement hypothesisdriven research. High data quality is critical for achieving scientific goals and for engaging users (Wood et al., 2011). VGI and carefully designed monitoring programs can minimize (or at least anticipate) the challenges requiring scientific control and sufficient randomization and replication of data collection and thus enhance the scientific credibility of the monitoring endeavor. Such programs have a higher likelihood of contributing positively to management and policy decisions (Wiersma, 2010).

The use of volunteer "citizen scientists" as part of long-term monitoring projects is not a new concept in avian studies. Birds are very charismatic and attract millions of passionate amateur "birders" worldwide. Many of these amateurs have been so dedicated that they become non-professional ornithologists who performed high quality studies, so that in no other scientific discipline amateurs had such an historic impact (Barrow, 1998). Recognizing this potential, several leading bird non-governmental organizations (NGOs) and academic institutions developed the methodologies for harnessing citizen participation (Sullivan et al., 2009). The use of citizen science in ornithology dates back more than a century, with projects that have a long history of volunteer-collected data (e.g. Sauer et al., 1966; Cohn, 2008; Risely et al., 2008; Bonney et al., 2009; Wood et al., 2011). In Portugal, the Society for the Study of Birds (SPEA), an environmental Portuguese NGO affiliated to BirdLife International, promotes and leads several citizen sciencebased projects involving bird censuses since 2004 (SPEA, 2015). For studies on avian ecology, data from citizen science projects offer the ability to test hypotheses at spatial and temporal scales never before possible.

\subsection{The Azores Bullfinch conservation issues}

The Azores Bullfinch Pyrrhula murina (Priolo) is confined to a small mountain area in the east of the island of São Miguel (Archipelago of the Azores, Portugal), where it was abundant and regarded as a pest of orange orchards in the 19th century, but never recorded in the west of the island or anywhere else outside São Miguel. It became difficult to observe after 1920, and believed to be almost extinct until the 1960s (Bannerman and Bannerman, 1966; Van Vegten, 1968). The historical decline of this endemic species and its present small range (area of occupancy $=83 \mathrm{~km}^{2}$; Ceia et al., 2011a) likely resulted from the widespread clearance of native forest for pastureland and forestry plantations of Cryptomeria japonica, and more recently, the spread of alien invasive plant species (especially Hedychium gardnerianum, Clethra arborea and Pittosporum undulatum; Ramos, 1995, 1996a; Aubrecht, 2000; Ceia et al., 2011a,b; Gil et al., 2011a, 2013, 2014) which replace the natural vegetation, suppressing the native biodiversity (Heleno et al., 2009) and reducing the regeneration of the natural vegetation (Ceia et al., 2011b; Heleno et al., 2010). The native laurel forest is now restricted to steep slopes, mostly above $400 \mathrm{~m}$ of altitude, limiting the Azores Bullfinch distribution which is entirely dependent on native forest for food during most months of the year (Ramos, 1995; Ceia et al., 2011b). The diet changes seasonally from herbaceous and fleshy fruit seeds in summer and autumn to fern sporangia, tree seeds, fern fronds and flower buds in winter and spring, comprising about 37 different plants species (Ramos, 1995). Most of the plant foods are native from the Azores laurel forest, particularly during winter and spring, although seeds from the exotic C. arborea may be a critical food in December-February (Ramos, 1996b; Ceia et al., 2011b). In summer and autumn birds forage mostly in forest clearings and bare ground areas along streams and forest margins (Ramos, 1996a). As a result of the strong dependence of the Azores Bullfinch from the native laurel forest, it can be regarded as a suitable flagship, umbrella and indicator species for this habitat. Monitoring the size and distribution of this species has been an important task of each conservation project, but difficult given the inaccessible terrain, very dense vegetation and discrete habits of the Azores Bullfinch. A species action plan was prepared in the 1990s (Ramos, 1996c) and a Special Protection Area (SPA; Natura 2000 site) was created in 1999 (Pico da Vara/Ribeira do Guilherme SPA). Several conservation projects financed by the LIFE program of the European Union followed and a management plan was developed and started being implemented in 2005 (Gil, 2005; Gil et al., 2011b).

\subsection{Standard scientific approaches for bird census}

A reliable estimate of population size is absolutely vital to timely inform the conservation efforts of threatened species. Without this information, it is virtually impossible to assess conservation status, identify the main threats and to monitor the effect of potential conservation actions (Burfield and van Bommel, 2004). Furthermore, having mid- and long-term population estimates is pivotal to disentangle normal fluctuations on population size from persistent trends resulting from environmental threats (i.e. declines), or from management actions (i.e. population recovery), thus being central for a proper adaptive management (McCarthy and Possingham, 2007).

Several methods have been classically applied to estimate rare bird population sizes, each of them with particular opportunities and caveats (Bibby et al., 2000). The application of capture-recapture techniques after individually banding birds, can be highly informative, for example to track elusive species, however its application requires a very high sampling effort, particularly for rare species (Bibby et al., 2000; Dunn and Ralf, 2004). Territory mapping can provide detailed information relative to the breeding or social status of the population, but it is impractical on elusive or rare species over large areas (Bibby et al., 2000). Distance sampling techniques applied on data collected along point or transect counts are often recommended as the most effective technique to estimate bird densities and evaluate population trends (Ralph et al., 1993; Dobkin and Rich, 1998).

All of the above methods have been tried to monitor the Azores Bullfinch population over the last two decades with different levels of success (Monticelli et al., 2010; Ceia et al., 2011a,b; Bastos et al., 2012). Unfortunately, the Azores Bullfinch population offers important logistic constraints, which hindered the conclusions derived from classic census techniques, namely: (1) the extremely steep terrain ( $94 \%$ of its distribution area has a slope greater than 20\%; Gil, 2005) combined with dense vegetation makes most of the distribution area inaccessible or severely restricts observer movement; (2) the small population size renders the use of capture-recapture methods and randomly distributed census across the whole distribution area highly cost-ineffective; (3) different plant/food phenology due to the strong altitudinal window hindered the uniform sampling of the area in space and time; and (4) the species is not evenly distributed but it decreases sharply with altitude and distance to roads, which are probably used differently by birds.

\subsection{The Priolo Atlas initiative}

Annual monitoring of Azores Bullfinch population trend started in 1991, although there was a hiatus from 1997 to 2001. 


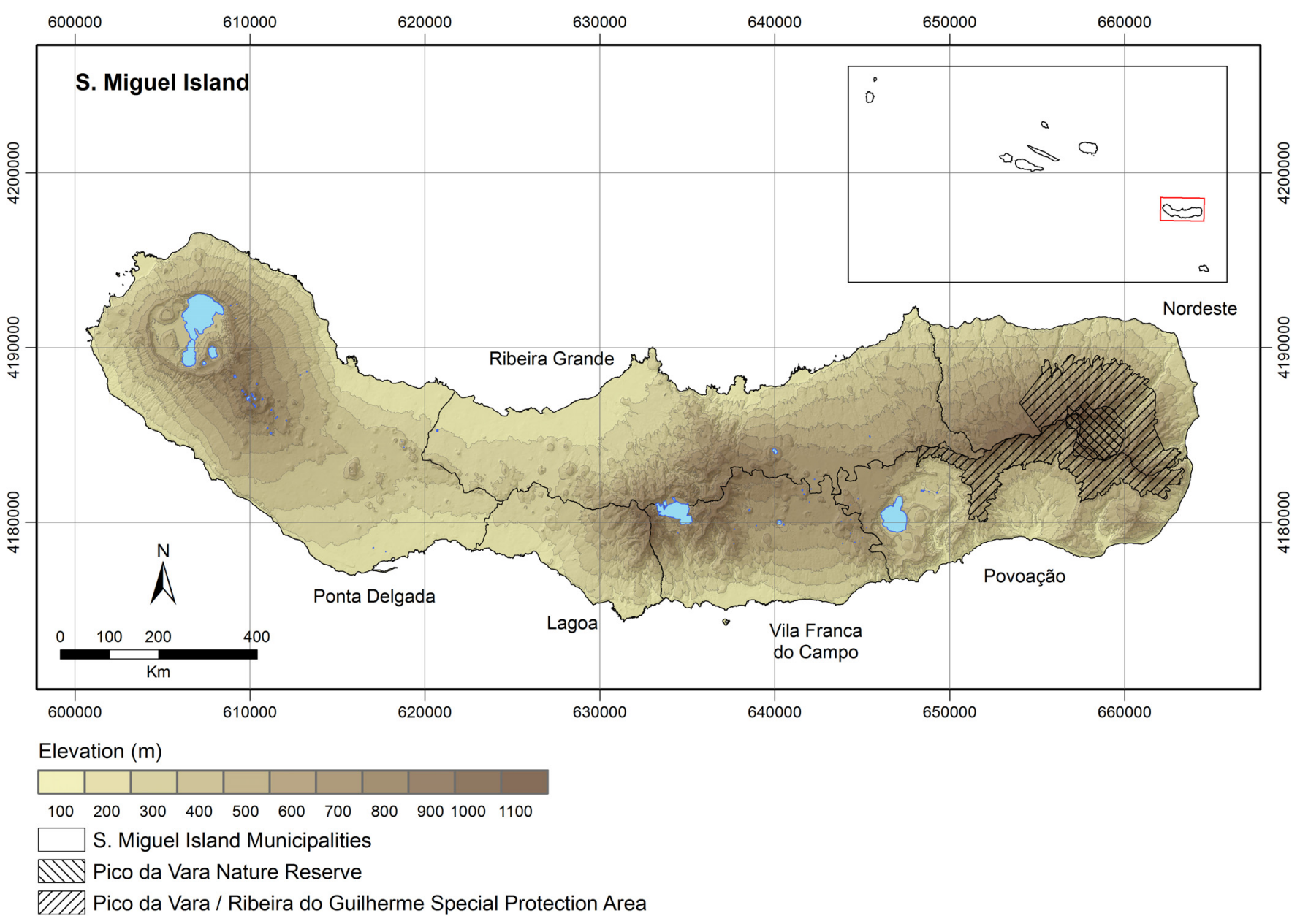

Fig. 1. Location of Pico da Vara Nature Reserve and Pico da Vara/Ribeira do Guilherme SPA in São Miguel Island (Azores, Portugal).

Point-counts were chosen as the sampling method, since line transects are impractical in the very steep and uneven terrain. Point-count stations were set at approximately $200 \mathrm{~m}$ intervals along non-random routes within areas of known occurrence of Azores Bullfinch. Five routes were initially defined comprising 99 point-count stations which were used from 1991 to 1996. In 2002, four new routes were added, although the number of point-count stations on each route varied over the next 4 years totaling 146 , 164,153 and 153 point-counts, respectively. In 2006, a new route was added, setting the number of point-count stations to 192 , distributed along 10 routes. Due to the difficult access to the area, census was limited to existing trails or roads, since also the human resources allocated to the census were limited to one observer each year. It took 1-2 months to complete the census, being impossible to conduct a more extensive cover of Pico da Vara/Ribeira do Guilherme SPA. It was therefore impossible to comply with some of the assumptions of the statistical data treatments decreasing the accuracy of the population estimates (e.g. randomized points; no double counts).

These difficulties lead in 2007 the Scientific Advisory Board of the LIFE Azores Bullfinch Project (LIFE03 NAT/P/000013) to discuss an alternative method to monitor the whole species population. It was considered that the best method would imply a random grid of points covering all the known distribution area and the need to sample all these points almost simultaneously (in one morning). For the scale needed, around 300 points were estimated to be a feasible solution. Due to the lack of access and to a possible average of 5-6 points performed per person, around 50 people would be needed to complete this one morning's complete atlas. Since it was an endemic species occurring at one of the most unknown Portuguese protected areas, the attractiveness to volunteers was considered high and therefore it was decided to organize the Priolo Atlas initiative to be based on a large network of volunteers/observers.

\section{Methods}

\subsection{Study area}

The Azores Archipelago is composed of nine inhabited islands located in the central North Atlantic Ocean. Pico da Vara/Ribeira do Guilherme SPA (6067 ha) is located in São Miguel, the largest and most populated island in the Azores. It includes one of the last main areas of native forest and scrubland in this island, whose most important sub-area is located in the mountain complex of Serra da Tronqueira (Fig. 1). The area is characterized by a temperate oceanic climate with small temperature range, high relative humidity and moderate rainfall spread evenly throughout the year (Silva and Smith, 2004).

This study was set in the eastern part of São Miguel Island, encompassing Pico da Vara/Ribeira do Guilherme SPA and other contiguous areas where the occurrence of the Azores Bullfinch was known or hypothesized. Most sampled habitats were located in mountainous areas with steep ground and densely vegetated with native and exotic flora (C. japonica plantations, $P$. undulatum patches, Laurel forest at various stages of invasion by $C$. arborea and $H$. gardnerianum, Macaronesian heaths and active raised bogs) 
but some human-dominated habitats were also sampled (pastures, agricultural fields, road edges, logged areas, and urban limits).

\subsection{Survey design}

The Priolo Atlas was designed to obtain population size and range size (extent of occurrence and area of occupancy) estimates for the Azores Bullfinch on every 4 years, starting in 2008. Due to the very difficult and uneven terrain, point-counts were chosen as the sampling method.

A methodical design was created by setting point-counts at the corners and center of UTM $1 \mathrm{~km}^{2}$ units wherein non-systematic records of Azores Bullfinch had been obtained since June 2005, as well as a buffer of UTM $1 \mathrm{~km}^{2}$ units around the first ones. Some buffer-units were excluded based on inadequate habitat requirements for the Azores Bullfinch (Ramos, 1995, 1996a; Ceia et al., 2009). In total, this survey consisted of 307 point-count stations which were installed in 152 UTM $1 \mathrm{~km}^{2}$ units. As the Priolo Atlas was to be repeated every 4 years, the UTM coordinates of pointcount stations were tracked to mark their respective locations in the terrain. In order to ensure logistics and observers' safety in very steep and difficult terrain, some point-count stations were not marked at their exact location and, in average, stations were set $67 \pm 6 \mathrm{~m}$ (mean $\pm \mathrm{SE}$ ) away from the designed location. On the weeks preceding each Priolo Atlas, access routes were manually opened and signalized with colored tape and spray so that point-count stations could then be easily reached by observers. To complete all point-counts in the shortest period of time, avoiding any bias caused by birds' movements along time, 48 and 54 observers were recruited in 2008 and 2012, respectively. Each edition of the Priolo Atlas was carried out in a single morning (26th June 2008 and 28th June 2012) between 06:30 and 11:00 in the absence of rain or heavy mist.

Point-count sampling used the variable circular plot method (VCPM; Reynolds et al., 1980), which involves the measurement or estimation of the distance from each detection to the observer during a finite counting period. After arriving at point-count stations, observers waited $1 \mathrm{~min}$ in order to reduce the effect of observer disturbance and then recorded all aural and visual detections of Azores Bullfinch during 8 min. Buckland et al. (2001) suggest that a quick count of birds after a prescribed waiting period is preferable to standard counting time period in order to yield a "snapshot" or instantaneous recording of birds more in line with the underlying assumptions of distance sampling. Following these recommendations, a "snapshot count" was conducted in parallel and it was set precisely 5 min after arrival at the point. In the case that any Azores Bullfinch was flushed by the arrival of observers at the station, these birds were recorded in the counts and a distance estimate made to the point from which they departed. The approximate location of all birds during the counts was noted on maps or recorded using GPS equipment. Birds heard or seen outside the counting period, e.g. while moving between stations, were recorded separately to enhance an exact delimitation of the extent of occurrence and area of occupancy.

\subsection{Training}

In order to collect high quality data it is imperative to have conscientious, motivated, competent and well-trained observers, with a good understanding of the data collection requirements (Kepler and Scott, 1981; Marques et al., 2001). A full training program involving Azores Bullfinch identification, survey methods and data recording, with a strong emphasis on improving distance estimation, was undertaken by all observers during the 3 days preceding the day of the Atlas. Field training on distance estimation to visual and aural cues in forest was complemented by specific training exercises which improved observers' abilities to estimate distances and allowed an evaluation of their accuracy. These exercises consisted of six simulated point-count stations, around which five colored tape marks were placed at known distances relatively close to the recorder $(0-25 \mathrm{~m})$. At each station, observers estimated the distance to each mark and at the end of each station the real distances were revealed. Errors in estimated distances decreased along the six simulated point-counts, ending at $11.9 \% \pm 1.1$ (mean $\pm \mathrm{SE}$ ). During field training, observers paced their distance estimates to improve their accuracy. During the Atlas the distance to each detection, when possible, was confirmed to the nearest meter by pacing, or using a metric tape or laser rangefinder after the 8-min count.

\subsection{Annual monitoring}

A program was developed to evaluate Azores Bullfinch population trend in the years between the realizations of each Priolo Atlas. This was carried out annually by a single observer in the period from 1 st June to 15 th July and consisted in conducting 158 point-counts, corresponding to the stations where birds were detected during the 2008 census as well as the surrounding stations. Point-counts were carried out between 06:30 and 11:00 in the absence of rain or heavy mist and all aural and visual detections of Azores Bullfinch were recorded during $8 \mathrm{~min}, 1 \mathrm{~min}$ after observer arrival to each station.

\subsection{Data analysis}

\subsubsection{Population size}

Data from the "snapshot count" were analyzed using the software DISTANCE v. 6.2 (Thomas et al., 2010) to calculate densities (individuals ha ${ }^{-1}$ ) in each census. Given that in the 2012 edition point-count stations were not surveyed in their totality $(n=297)$, the models estimating density of the Azores Bullfinch in 2008 and 2012 used here only a subset of all data (297 samples in both years). This allowed a proper comparison between the two editions of the Priolo Atlas despite of violating distance sampling assumptions (Buckland et al., 2001). Modeling used the conventional distance sampling analysis testing the four available key functions (uniform, half-normal, hazard-rate and negative exponential) with cosine series expansion. Detection functions were selected using the version of Akaike's Information Criterion corrected for small sample size (AICc) (Akaike, 1974; Burnham and Anderson, 1998). Model selection was guided by $\chi^{2}$ model-fit statistics, and visual inspection of detection probability and probability density plots (Buckland et al., 2001). An absolute population size estimate was obtained by multiplying computed density estimates by the total sampled area (15,200 ha).

\subsubsection{Range size}

As recommended by IUCN (2001), the extent of occurrence of Azores Bullfinch population was calculated by a minimum convex polygon (the smallest polygon in which no internal angle exceeds $180^{\circ}$ ) containing all locations where birds were recorded during each edition of the Priolo Atlas while the area of occupancy was calculated as the sum of the occupied UTM $1 \mathrm{~km}^{2}$ units.

\subsubsection{Population trend}

Population trend was obtained by calculating the population index for each year, derived from the annual monitoring. The number of birds detected at each point-count was modeled using a general linear model (GLM), entering year as explanatory variable, and a Poisson distribution with log-link function was used. This analysis was run using the software STATISTICA v. 7.0 (Statsoft Inc, 2004). 
Table 1

Density estimates computed with DISTANCE software using data from the variable circular plot method ("snapshot count").

\begin{tabular}{|c|c|c|c|c|c|c|c|}
\hline Data filter & Number of observations & Density (birds ha ${ }^{-1}$ ) & Key function & $\% \mathrm{CV}$ & $95 \%$ CI LL & $95 \% \mathrm{CI} U \mathrm{~L}$ & $P\left(X^{2}\right)$ \\
\hline 2008 & 25 & 0.22 & Hazard-rate (2) & 38.51 & 0.11 & 0.46 & 0.200 \\
\hline 2012 & 29 & 0.26 & Hazard-rate (2) & 37.54 & 0.12 & 0.52 & 0.200 \\
\hline
\end{tabular}

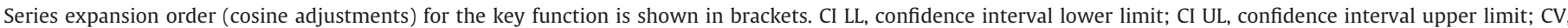
coefficient of variation.

\section{Results and discussion}

During the 2008 edition of the Priolo Atlas there were a total of 422 observations (90 at point-count stations, plus 322 in between point-count stations). In the second edition of the Atlas the total number of observations was higher, producing 471 observations (87 at point-count stations, plus 384 in between point-count stations).

\subsection{Population size}

Using the "snapshot count" (birds detected exclusively at minute 5) at 297 point-count stations, 25 Azores Bullfinch records were obtained in 2008 and 29 records in 2012, corresponding to detections at 19 and 21 point-count stations, respectively. A minimum of 60 observations is recommended to estimate density with a reasonable degree of accuracy (Buckland et al., 2001). Therefore we used a global detection function to analyze data from the two editions of the Priolo Atlas. A $X^{2}$ test indicated that model had a good fit and none of the four critical assumptions of distance sampling was seriously violated (Lloyd et al., 1998; Table 1). Computed density for the Azores Bullfinch in 2012 was 0.26 birds ha $^{-1}$ (\% CV = 37.54) and corresponded to an increase of $18.2 \%$ in relation to the density estimate obtained for 2008 ( 0.22 birds ha $^{-1}$ ) (Table 1$)$. The Azores Bullfinch population size estimates $(95 \% \mathrm{CI})$ obtained for 2008 and 2012 were 3344 (1672-6992) individuals and 3952 (1824-7904) individuals, respectively.

\subsection{Range size}

The total number of individuals recorded during the Atlas' morning (i.e. during point-counts, and in between point-counts) was used to calculate the extent of occurrence of the species, on the basis of their spatial distribution. In 2008 the calculated extent of occurrence was of $144 \mathrm{~km}^{2}$, whereas in 2012 it was of $137 \mathrm{~km}^{2}$ (Fig. 2). The area of occupancy was estimated in $83 \mathrm{~km}^{2}$ and $90 \mathrm{~km}^{2}$, in 2008 and 2012, respectively.

\subsection{Population trend}

The number of individuals detected during annual monitoring, established in 2008, was lowest in $2012(n=70)$ and highest in 2013 $(n=119)$ (Table 2).

The GLM results showed that there were no significant differences between model's coefficients for each year and that of 2008 , the reference year (Fig. 3). The population index for the period 2008-2014 shows considerable fluctuation, although a slightly increasing trend seems to be emerging, particularly since 2010 . Such trend is however overshadowed by the large width of the 95\% confidence intervals (Fig. 3) arising from the high number of sampled point-counts with no birds detected.

\subsection{Long term population trend and the importance of the Priolo Atlas}

Due to its low abundance, low conspicuity and the remarkable inaccessibility of its distribution area, the Azores Bullfinch population is particularly challenging to monitor. Such difficulty in obtaining reliable estimates of population size is reflected in the large confidence intervals both of the annual monitoring censuses (Fig. 3), and of the two Priolo Atlases of 2008 and 2012 (Table 1 ). While such uncertainty on tracking population trends over short term makes it difficult to establish strong causal relationships between ecological management and population dynamics, two general trends can be inferred with confidence from these studies: (1) the population of the Azores Bullfinch has been mostly stable and certainly not declining since 2006; and (2) the population since 2006 is considerably higher than it was in the late 90s, which in turn is considerably higher than it was in the beginning of the last century (Ceia et al., 2011a).

This recent trend and particularly the Atlas of 2008 have been pivotal to support the IUCN decision of downgrading the conservation status of the Azores Bullfinch from critically endangered to endangered (Ceia et al., 2011a). Based on the Atlases results, it has been suggested that the population have slightly expanded (more individuals, higher density and larger distribution area) between 2008 and 2012. Such a "recovery" seems a plausible result of the large scale habitat restoration program implemented by SPEA and several partners throughout the SPA since 2003, which improved the quality of ca. 350 ha of native laurel forest and other native habitats in the species core area (SPEA, 2006; Heleno et al., 2010; Bastos et al., 2012). This slow positive trend seems to receive some support from the annual census data, even if the large confidence intervals of the estimates hinder the identification of statistically significant changes. The possibility to simultaneously censing the whole distribution area of the Azores Bullfinch and eliminating the confounding effect of seasonal movement of birds tracking temporal food resources is a major advantage of the Priolo Atlas over the standard methodology. However only two events (2008 and 2012) clearly do not suffice to provide solid conclusions about the population trends. In this respect we believe that the results of the next years' Atlas will be instrumental, particularly for contrasting the changes on bird density between specific areas subject to habitat management and those that have not been managed. The data collected during the Priolo Atlas has also been used to feed distance sampling approaches (Ceia et al., 2011a) and to develop an innovative stochastic-dynamic modeling approach that allows to predict in silico different conservation scenarios (Bastos et al., 2012).

The Priolo Atlas is therefore an absolutely critical tool to monitor the population of this endemic species. The regular repetition of this methodology in the long-term is particularly important to closely evaluate the likely effects of the pervasive threat posed by aggressive invasive plants that seriously simplify the laurel forest plant and insect communities (Heleno et al., 2009), outcompeting important food sources for the Azores Bullfinch (Ramos, 1995; Ceia et al., 2011b).

Importantly, the value of the approach will be dependent on the capacity to repeat a methodology and effort as constant as possible in future editions, and resisting the temptation of constantly "improving" the sampling protocols (Likens, 1989). This approach might prove extremely useful to detect population trends of rare species which due to the characteristics of their distribution areas cannot be accurately evaluated with classic census techniques. 

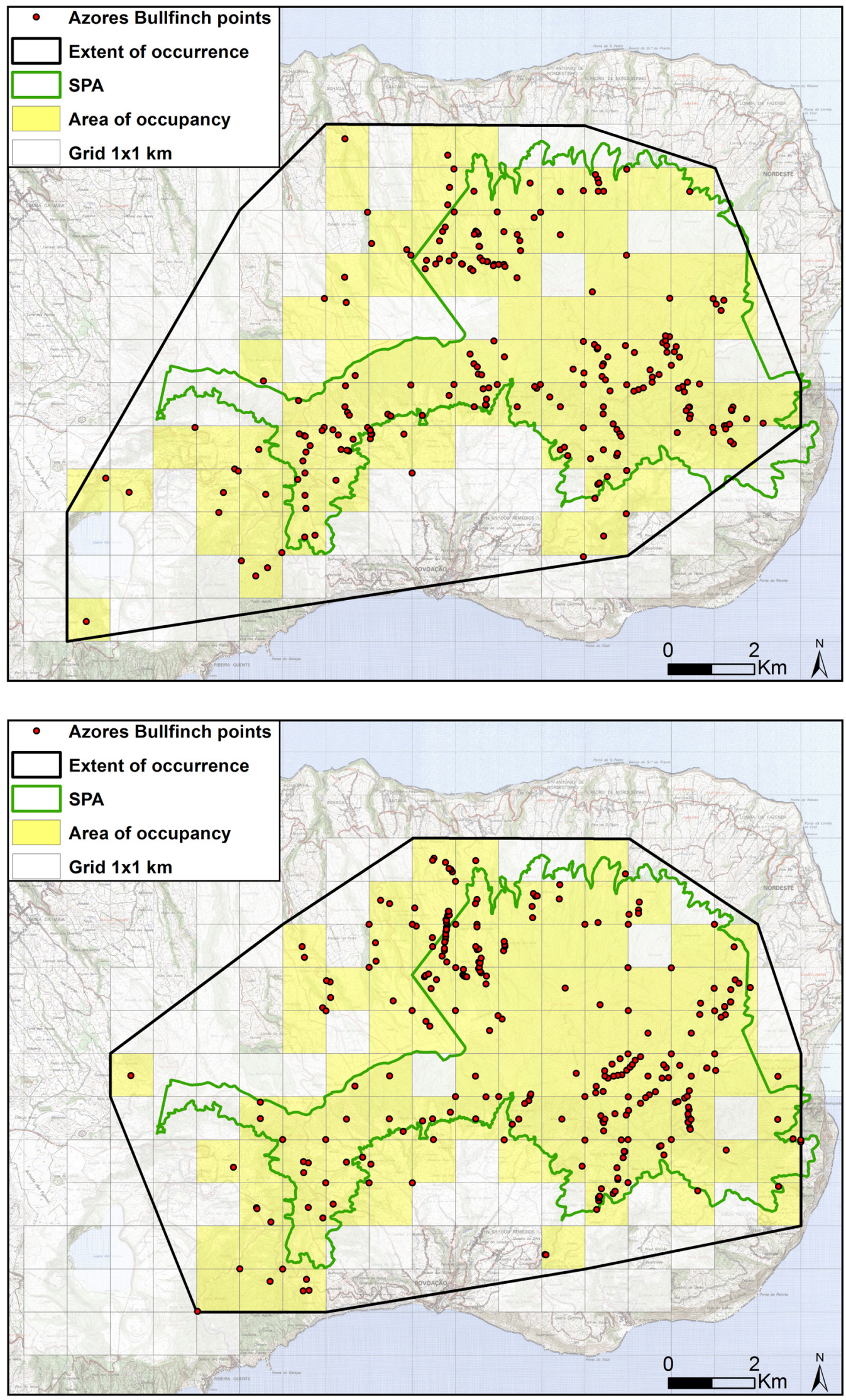

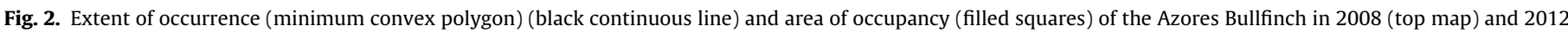
(bottom map).

Adapted from Ceia et al. (2011a) and Veríssimo (2013). 
Table 2

Evolution of the number of Azores Bullfinches detected, and number of point-count stations where birds were present between 2008 and 2014.

\begin{tabular}{|c|c|c|c|c|c|c|c|}
\hline & 2008 & 2009 & 2010 & 2011 & 2012 & 2013 & 2014 \\
\hline Detections & 90 & 84 & 70 & 98 & 71 & 119 & 107 \\
\hline Points with detections & 48 & 41 & 41 & 53 & 40 & 52 & 51 \\
\hline
\end{tabular}

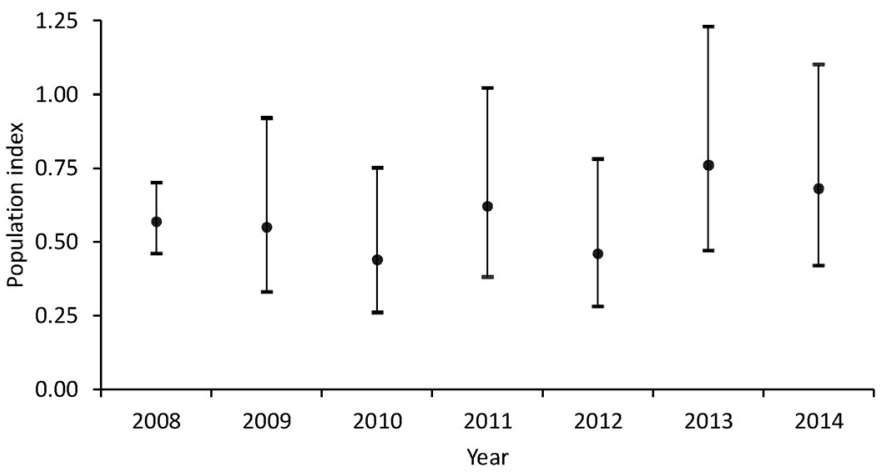

Fig. 3. Population index ( $95 \%$ confidence interval) calculated from the GLM on the number of individuals detected on point-counts, for the 2008-2014 period. Adapted from Coelho (2014).

\subsection{VGI in the Priolo Atlas context}

One of the challenges of relying on volunteers is to overcome potential sources of error inherent to a diverse group of observers with different skill levels and familiarity with the object of study, which, to a certain extent, is not under the control of the experts (Wiersma, 2010). In this respect, the training program aimed at the detectability and identification of the Azores Bullfinch, improving distance to individuals estimate, and data recording, was vital to secure high quality data (Kepler and Scott, 1981; Marques et al., 2001). The reliability of a true monitoring scheme is dependent on the ability to repeat accurately its procedures, so results can be compared, and thus the importance of registering information on the location of the point-count stations. This allowed the replication of procedures at the same locations during each Priolo Atlas edition, and reliable comparisons of population estimates. Also it serves the purposes of the annual monitoring, though this runs over a more extended length of time, since the annual census used the same locations (see Section 2 for details on the differences between Priolo Atlas and the annual monitoring), thus allowing for comparable results of the population index, and a reliable assessment of the population trends of the Azores Bullfinch.

\section{Conclusions and future outlook}

The Priolo Atlas is a perfect example of the value of engaging common citizens with scientific research in a way that potentiates scientific advances that translate into practical conservation outputs. At the same time the activity allows an enriching experience for the participants, and attracts media attention to the region and to the problematic of nature conservation as a whole.

With the participation of citizens in the Priolo Atlas it is possible to acquire robust data on trends and distribution of the Azores Bullfinch, a flagship and umbrella species for the conservation of the whole laurel forest. The Priolo Atlas was particularly useful in defining precisely the extent of occurrence and area of occupancy of this endangered species. We will continue monitoring the Azores Bullfinch with this method as the next Atlas is planned for 2016. We hope that other conservationist get inspired with our work and devise similar methods for their own species.

\section{Acknowledgements}

Authors are particularly thankful to each one of the volunteers of Priolo Atlas in 2008 and 2012; to André Batista and Rita Bastos for important contributions toward establishing the Azores Bullfinch population trends; to María Luisa Arosa, Azucena de la Cruz, Carlos Silva, Carlos Pereira, Luis Costa, Thijs Valkenburg and Rui Botelho for valuable logistic support; to Aidnature for the video coverage; and to António Moniz for his cartographic support. The organization of the Atlas was funded by the following entities: Disney Worldwide Conservation Fund, Royal Society for the Protection of Birds (via José Pedro Tavares), BirdLife International Preventing Extinctions Programme, Azores Tourism Board, Azores Environment Secretary and LIFE Program (LIFE Priolo and LIFE + Laurissilva Sustentável). The participation of author Artur Gil in this study was supported by a FCT-based Post-Doctoral Research Project (reference SFRH/BPD/100017/2014), funded by the National Budget of the Ministry of Education and Science of Portugal and by the European Social Fund.

\section{References}

Akaike, H., 1974. A new look at the statistical model identification. IEEE Trans. Autom. Control 19, 716-723.

Aubrecht, G., 2000. The Azores Bullfinch - Pyrrhula murina Godman - the history of a bird species: persecuted-missing-rediscovered-protected (?) (including a list of all known specimens and syntypes). Annalen des Naturhistorischen Museums in Wien. Serie B für Botanik und Zoologie 1866, 23-62.

Bannerman, D.A., Bannerman, W.M., 1966. Birds of the Atlantic Islands. 3. A History of the Birds of the Azores. Edinburgh Oliver \& Boyd.

Barrow, M.V., 1998. A Passion for Birds: American Ornithology After Audubon. Princeton University Press, Princeton.

Bastos, R., Santos, M., Ramos, J., Vicente, J., Guerra, C., Alonso, J., Honrado, J., Ceia, R., Timóteo, S., Cabral, J., 2012. Testing a novel spatially-explicit dynamic modelling approach in the scope of the laurel forest management for the endangered Azores Bullfinch (Pyrrhula murina) conservation. Biol. Conserv. 147, 243-254.

Bibby, C.J., Burgess, N.D., Hill, D.A., Mustoe, S., 2000. Bird Census Techniques, 2nd ed. Academic Press, London.

Bonney, R., Cooper, C.B., Dickinson, J., Kelling, S., Phillips, T., Rosenberg, K.V., Shirk, J., 2009. Citizen science: a developing tool for expanding science knowledge and scientific literacy. BioScience 59, 977-984.

Buckland, S.T., Anderson, D.R., Burnham, K.P., Laake, J.L., Borchers, D.L., Thomas, L. 2001. Introduction to Distance Sampling: Estimating Abundance of Biological Populations. Oxford University Press, Oxford.

Burfield, I., van Bommel, F., 2004. Birds in Europe: Population Estimates, Trends and Conservation Status. Birdlife International, Cambridge.

Burnham, K.P., Anderson, D.R., 1998. Model Selection and Inference: A Practical Information-Theoretic Approach. Springer-Verlag, New York.

Ceia, R., Ramos, J.A., Heleno, R., Hilton, G., Marques, T., 2011a. Status assessment of the critically endangered Azores Bullfinch. Bird Conserv. Int. 21, 477-489.

Ceia, R., Sampaio, H., Parejo, S., Heleno, R., Arosa, M., Ramos, J.A., Hilton, G., 2011b. Throwing the baby out with the bathwater: does laurel forest restoration remove a critical winter food supply for the critically endangered Azores Bullfinch? Biol. Invasions 13, 93-104.

Ceia, R., Heleno, R., Ramos, J.A., 2009. Summer abundance and ecological distribution of passerines in native and exotic forests in São Miguel, Azores. Ardeola 56, 25-39.

Coelho, R., 2014. Monitorização de Azores Bullfinch Pyrrhula murina 2014. Sociedade Portuguesa para o Estudo das Aves, Lisboa, Portugal (unpublished report).

Cohn, J.P., 2008. Citizen science: can volunteers do real research? BioScience 58, 192-197.

Cooper, C.B., Shirk, J., Zuckerberg, B., 2014. The invisible prevalence of citizen science in global research: migratory birds and climate change. PLOS ONE 9, e106508.

Devictor, V., Whittaker, R.J., Beltrame, C., 2010. Beyond scarcity: citizen science programmes as useful tools for conservation biogeography. Divers. Distrib. 16 354-362.

Dickenson, J.L., Zuckerberg, B., Bonter, D.N., 2010. Citizen science as an ecological research tool: challenges and benefits. Annu. Rev. Ecol. Evol. Syst. 41, 149-172. 
Dobkin, D.S., Rich, A.C., 1998. Comparison of line-transect, spot-map, and pointcount surveys for birds in riparian habitats of the Great Basin (Comparación de Monitoreos por Transectos lineares Mapas de Puntos, y Conteos por Puntos para Aves en Hábitats Riparios de la Gran Cuenca). J. Field Ornithol., 430-443.

Dunn, E., Ralf, C.J., 2004. Use of mist nets as a tool for bird population monitoring. Stud. Avian Biol. 29, 1-6.

Gil, A., Yu, Q., Abadi, M., Calado, H., 2014. Using ASTER imagery for mapping invasive Pittosporum woodland in Pico da Vara Natural Reserve (Azores Islands Portugal). Rev. Arvore 38, 391-401.

Gil, A., Lobo, A., Abadi, M., Silva, L., Calado, H., 2013. Mapping invasive woody plants in Azores protected areas by using very high-resolution multispectral imagery. Eur. J. Remote Sens. 46, 289-304.

Gil, A., Yu, Q., Lobo, A., Lourenco, P., Silva, L., Calado, H., 2011a. Assessing the effectiveness of high resolution satellite imagery for vegetation mapping in small islands protected areas. J. Coast. Res. SI64, 1326-1330.

Gil, A., Calado, H., Costa, L.T., Bentz, J., Fonseca, C., Lobo, A., Vergílio, M., Benedicto, J., 2011b. A methodological proposal for the development of Natura 2000 sites management plans. J. Coast. Res. SI64, 1326-1330.

Gil, A., 2005. Management Plan of the Pico da Vara/Ribeira Special Protection Area. Sociedade Portuguesa para o Estudo das Aves, Nordeste, Portugal.

Goodchild, M.F., 2007. Citizens as sensors: the world of volunteered geography. GeoJournal 69, 211-221.

Heleno, R., Ceia, R., Ramos, J.A., Memmott, J., 2009. The effect of alien plants on insect abundance and biomass: a food web approach. Conserv. Biol. 23, 410-419.

Heleno, R., Lacerda, I., Ramos, J.A., Memmott, J., 2010. Evaluation of restoration effectiveness: community response to the removal of alien plants. Ecol. Appl. 20, 1191-1203.

IUCN, 2001. IUCN Red List Categories And Criteria: Version 3.1. IUCN Species Survival Commission, Gland, Switzerland; Cambridge, UK.

Kepler, C.B., Scott, J.M., 1981. Reducing bird count variability by training observers. Stud. Avian Biol. 6, 366-371.

Likens, G.E., 1989. Long-Term Studies in Ecology. Springer-Verlag, New York.

Lloyd, H., Cahill, A., Jones, M., Marsden, S., 1998. Estimating bird densities using distance sampling. In: Bibby, C, Jones, M, Marsden, S (Eds.), Expedition Field Techniques: Bird Surveys. Royal Geographical Society, London, UK, pp. 35-52.

Marques, F.C.F., Buckland, S.T., Goffin, D., Dixon, C., Borchers, D.L., Mayle, B.A., Peace, A.J., 2001. Estimating deer abundance from line transect surveys of dung: sika deer in southern Scotland. J. Appl. Ecol. 38, 349-363.

McCarthy, M.A., Possingham, H.P., 2007. Active adaptive management for conservation. Conserv. Biol. 21, 956-963.

Monticelli, D., Ceia, R., Heleno, R., Laborda, H., Timoteo, S., Jareno, D., Hilton, G.M., Ramos, J.A., 2010. High survival rate of a critically endangered species, the Azores Bullfinch Pyrrhula murina, as a contribution to population recovery. J. Ornithol. $151,627-636$.

Morzy, M., 2014. ICT Services for Open and Citizen Science. World Wide Web, pp. $1-15$.
Nascimento, S., Pereira, A.G., Ghezzi, A., 2014. From Citizen Science to do it Yourself Science. Joint Research Centre, European Commission, Ispra, Italy.

Newman, G., Zimmerman, D., Crall, A., Laituri, M., Graham, J., Stapel, L., 2010. Userfriendly web mapping: lessons from a citizen science website. Int. J. Geogr. Inf. Sci. 24, 1851-1869.

Ralph, C.J., Geupel, G.R., Pyle, P., Martin, T.E., DeSante, D.F., 1993. Handbook of Field Methods for Monitoring Landbirds. Pacific Southwest Research Station, Forest Service, U.S. Department of Agriculture, Albany, USA.

Ramos, J.A., 1996a. Introduction of exotic tree species as a threat to the Azores Bullfinch population. J. Appl. Ecol. 33, 710-722.

Ramos, J.A., 1996b. The influence of size, shape and phenolic content on the selection of winter foods by the Azores Bullfinch. J. Zool. Lond. 238, 415-433.

Ramos, J.A., 1996c. Action plan for the Azores Bullfinch (Pyrrhula murina). In: Heredia B, Rose, L, Painter, M (Eds.), Globally Threatened Birds in Europe: Action Plans. Council of Europe and BirdLife International, Strasbourg, France, pp. 347-352.

Ramos, J.A., 1995. The diet of the Azores Bullfinch Pyrrhula murina and the floristic variation within its range. Biol. Conserv. 71, 237-249.

Reynolds, R.T., Scott, J.M., Nussbaum, R.A., 1980. A variable circular plot method for estimating bird numbers. Condor 82, 309-313.

Risely, K., Noble, D.G., Baillie, S.R., 2008. The breeding bird survey 2007. BTO Res. Rep. 508 (3).

Robson, C.,(PhD Dissertation) 2012.Using Mobile Technology and Social Networking to Crowdsource Citizen Science. University of California, Berkeley, USA.

Sauer, J.R., Hines, J.E., Fallon, J., 1966. The North American Breeding Bird Survey. Results and Analysis, 2003.

Silva, L., Smith, C.W., 2004. A characterization of non-indigenous flora of the Azores Archipelago. Biol. Invasions 6, 193-204.

SPEA, 2015. Censos. WWW Document, http://www.spea.pt/pt/estudo-econservacao/censos/.

SPEA, 2006. Recuperação do habitat do Azores Bullfinch na ZPE Pico da Vara/Ribeira do Guilherme LIFE 03NAT/P/000013 - 2 Relatório de Progresso. Sociedade Portuguesa para o Estudo das Aves, Lisboa, Portugal.

StatSoft, Inc., 2004. STATISTICA (Data Analysis Software System), version 7

Sullivan, B.L., Wood, C.L., Iliff, M.J., Bonney, R.E., Fink, D., Kelling, S., 2009. eBird: a citizen-based bird observation network in the biological sciences. Biol. Conserv. 142, 2282-2292.

Thomas, L., Buckland, S.T., Rexstad, R., Laake, J.L., Strindberg, S., Hedley, S., Bishop J., Marques, T.A., Burnham, K.P., 2010. Distance software: design and analysis of distance sampling surveys for estimating population size. J. Appl. Ecol. 47, 5-14.

Van Vegten, J.A., 1968. The Azores Bullfinch is not extinct. Ardea 56, 14

Veríssimo, C., 2013. Monitorização de Priolo Pyrrhula murina 2012. Sociedade Portuguesa para o Estudo das Aves, Lisboa, Portugal (unpublished report).

Wiersma, Y.F., 2010. Birding 2.0: citizen science and effective monitoring in the Web 2.0 world. Avian Conserv. Ecol. 5, 13.

Wood, C., Sullivan, B., Iliff, M., Fink, D., Kelling, S., 2011. eBird: engaging birders in science and conservation. PLoS Biol. 9, e1001220. 